\title{
Effectiveness of Mass Media Campaigns to Improve Handwashing-Related Behavior, Knowledge, and Practices in Rural Bangladesh
}

\author{
Mahfuza Islam, ${ }^{1 \star}$ Jade Benjamin-Chung, ${ }^{2}$ Sonia Sultana, ${ }^{1}$ Leanne Unicomb, ${ }^{1}$ Monirul Alam, ${ }^{3}$ Mahbubur Rahman, ${ }^{1}$ Ayse Ercumen, ${ }^{4}$ \\ and Stephen P. Luby ${ }^{5}$ \\ ${ }^{1}$ Infectious Disease Division, Environmental Intervention Unit, icddr,b, Dhaka, Bangladesh; ${ }^{2}$ Division of Epidemiology and Biostatistics, University \\ of California, Berkeley, Berkeley, California; ${ }^{3}$ WASH Specialist, Water, Sanitation and Hygiene (WASH) Section, UNICEF, Dhaka, Bangladesh; \\ ${ }^{4}$ Department of Forestry and Environmental Resources, North Carolina State University, Raleigh, North Carolina; ${ }^{5}$ Woods Institute for the \\ Environment, Stanford University, Stanford, California
}

\begin{abstract}
Water, sanitation, and handwashing interventions that use intensive interpersonal communication improve targeted behaviors, but are expensive at scale. Mass media is an alternative that could reach more people at lower cost but has rarely been rigorously evaluated. We assessed the effectiveness of a mass media campaign in improving handwashing knowledge and practices in rural Bangladesh. We conducted a cross-sectional assessment before the campaign among 8,947 households and again after 4 months of the campaign among 8,400 different households in the same areas. Trained enumerators conducted spot checks of water, sanitation, and hygiene facilities, and recorded reported knowledge and practices. We compared these outcomes after versus before the campaign using generalized linear models with robust standard errors. After the media campaign, caregivers were more likely to recall $\geq 3$ messages regarding handwashing (prevalence ratio $[P R]=1.44,1.34-1.55)$, sanitation $(P R=1.45,1.35-1.55)$, and safe water $(P R=1.17,1.08-1.26)$. After the campaign, the prevalence of using soap and water during handwashing demonstrations was higher among caregivers $(P R=1.15,1.12-1.19)$ and children $(P R=1.31,1.22-1.41)$. Hands were more commonly observed to be visibly clean among caregivers $(P R=1.14,1.07-1.20)$ and children $(P R=1.13,1.05-1.21)$. Soap and water was more commonly observed in handwashing stations near latrines $(P R=1.12,1.06-1.19)$ and in cooking/eating places $(P R=1.09$, 1.01-1.18). Our findings indicate improved handwashing knowledge and behaviors following a mass media campaign. This promising approach can be deployed to improve water, sanitation, and hygiene practices at scale and should be evaluated in other contexts.
\end{abstract}

\section{INTRODUCTION}

Infectious diseases remain an important health problem for most low- and middle-income countries, including Bangladesh. Pathogens that can cause diarrhea and respiratory infections can be transmitted through contaminated hands, objects, foods, or water supplies. ${ }^{1-3}$ Simple measures like washing both hands with soap at key times can reduce $50 \%$ of diarrheal episodes by interrupting pathogen transmission. ${ }^{4}$ Handwashing with soap prevents about $30-47 \%$ of child diarrhea ${ }^{4,5}$ and $23 \%$ of respiratory infections. ${ }^{6,7}$ Hand hygiene is a critical strategy against the transmission of COVID-19 infection. ${ }^{8}$ Similarly, during the outbreak of SARS, observational evidence suggests that handwashing reduced viral spread. ${ }^{9}$ Frequent handwashing would reduce the risk of viral transmission by $55 \% .^{6,9}$ To prevent virus transmission, the U.S. CDC recommends frequent handwashing with soap and water for 20 seconds. $^{10}$

Despite its protective effect, the practice of handwashing with soap remains suboptimal. In low- and middle-income countries, only $3-34 \%$ of people routinely wash their hands with soap at critical times, ${ }^{11}$ and hands were washed with soap on only about $5-15 \%$ of key occasions such as after the toilet or after cleaning up a child. ${ }^{12}$ Not having a specific location with soap and water available, especially after leaving the toilet, is a common major environmental constraint to optimal handwashing. ${ }^{13}$ In addition, local culture, beliefs, traditions, and norms are some social factors that also

*Address correspondence to Mahfuza Islam, Infectious Disease Division, Environmental Intervention Unit, Enteric and Respiratory Infections, icddr,b, 68, Shaheed Tajuddin Ahmed Sarani, Dhaka 1212, Bangladesh. E-mail: mi_sheuli@icddrb.org influence caregiver handwashing behavior that are promulgated through social structures such as the family, neighbors, local social organizations, government health workers, schools, and mass media. ${ }^{13}$ Although the benefits of handwashing with soap are clear, encouraging people to adopt a habit of regular handwashing has proved difficult.

Studies that have achieved high adherence to handwashing have typically implemented sustained daily to fortnightly contact between promoters and participants ${ }^{14-17}$ that is costly and not necessarily scalable. ${ }^{18}$ In an assessment of the Sanitation, Hygiene Education, and Water Supply in Bangladesh Program (SHEWA-B), a large-scale program to improve water, sanitation, and hygiene in Bangladesh through inperson promotion, approximately half of respondents did not recall ever meeting a SHEWA-B hygiene promoter. ${ }^{18}$ Mass media is an alternative that could reach more people at lower cost, but it has not been rigorously evaluated. Media campaigns have been used to alter various health behaviors, including tobacco, alcohol, and illicit drug use; cancer screening and prevention; sexual behaviors; child care; and many other health-related issues. The outcomes of these efforts have been mixed, although there have been some notable successes. ${ }^{19}$ Evaluations of mass media campaigns to discourage dangerous alcohol consumption, ${ }^{20}$ to reduce exposure to arsenic contaminated water in Bangladesh, ${ }^{21}$ to promote vaccination in Zambia, ${ }^{22}$ and to prevent obesity ${ }^{23}$ concluded that these campaigns enhanced knowledge about the promoted topic, but did not affect behavior.

UNICEF along with the government of Bangladesh implemented the SHEWA-B program in 2007 , which was among the largest intensive water, sanitation, and hygiene quality improvement programs ever attempted in a low-income country. Intervention methods included dissemination of key hygiene 
messages among targeted population through household visits, courtyard sessions, tea stall sessions, fairs, and interactive popular theaters. The program was designed to make improvements in hygiene practices, particularly handwashing with soap. At a smaller scale, the program also targeted provision of arsenic-safe water and improved sanitation facilities.

The International Centre for Diarrhoeal Disease Research, Bangladesh (icddr,b) conducted a health impact evaluation of the SHEWA-B intervention. This assessment included a baseline evaluation of SHEWA-B in 2007 and a midline evaluation in 2009 that compared the extent of behavior change with prespecified targets. Changes were apparent in only a handful of the outcome indicators; modest changes in observed handwashing after fecal contact became evident as early as 1 year after implementation, but there was little additional change in the second year. ${ }^{24}$ After 2 years, participants washed their hands with soap $<3 \%$ of the time around food-related events in both intervention and control households, washing both hands with soap or ash after cleaning a child's anus increased from $22 \%$ to $36 \%$, and no access to a latrine decreased from $10 \%$ to $6.8 \%$; there was no difference in diarrhea or respiratory disease in children younger than 5 years living in households that had received the intervention compared with control households. ${ }^{24}$

Although the failure to achieve midline targets was disappointing, these findings provided an unambiguous signal that the program would need to change to achieve its goals. In response, UNICEF and the Department of Public Health Engineering of the government of Bangladesh implemented substantial changes in an effort to improve the effectiveness of the SHEWA-B interventions. These improvements included a more targeted and specific behavior change strategy to improve the frequency of handwashing with soap, as well as some messaging encouraging use of arsenic-free safe water for both cooking and drinking, and use of sanitary latrines for defecation and to discard child feces. Therefore, they reduced the number of key messages that were delivered. Another major change was that mass media was used to deliver the messages rather than in-person promotion. In this study, we assess the effectiveness of the mass media campaign in improving handwashing-related behavior, knowledge, and practices in rural Bangladesh.

\section{METHODS}

Mass media campaign. Sanitation, Hygiene Education, and Water Supply in Bangladesh Program was a 5-year project implemented by the government of Bangladesh and UNICEF. The program aimed to provide handwashing messaging to approximately 19 million people living in urban and rural areas of Bangladesh, as well as delivered information on safe water and sanitation at a smaller scale. The program focused on 58 subdistricts (upazilas) of 16 districts and 300 para centers from eight subdistricts in the three Chittagong Hill Tract districts. UNICEF implemented a mass media campaign in two phases: November 2011 to February 2012 and again from October to December 2012. As part of this campaign, television and radio spots were used to convey SHEWA-B messages (Figure 1). From November 2011 to February 2012, 1,814 radio spots and 458 television spots were aired for handwashing and sanitation. These messages were again aired with the addition of safe water messages from October to December

\begin{tabular}{|c|c|c|c|}
\hline \multicolumn{2}{|c|}{ Hand washing (with soap) messages } & \begin{tabular}{|l|} 
Sanitation Messages \\
- Use sanitary \\
\end{tabular} & \begin{tabular}{|c|c}
$\begin{array}{c}\text { Safe water messages } \\
\text { (arsenic only) }\end{array}$ \\
- & Encouraged arsenic \\
\end{tabular} \\
\hline $\begin{array}{l}\text { AUDIO/Radio } \\
\text { coverage ---- } \\
\text { - After } \\
\text { defecation } \\
\text { - After } \\
\text { cleaning a } \\
\text { child who } \\
\text { defecated } \\
\text { Before } \\
\text { feeding a } \\
\text { child } \\
\text { Before food } \\
\text { preparation }\end{array}$ & $\begin{array}{l}\text { VIDEO/Television } \\
\text { coverage ---- } \\
\text { - After defecation } \\
\text { - After cleaning a } \\
\text { child who } \\
\text { defecated } \\
\text { - Before feeding a } \\
\text { child } \\
\text { - Before food } \\
\text { preparation } \\
\text { - Before touching } \\
\text { and caring of } \\
\text { babies }\end{array}$ & $\begin{array}{l}\text { - Use sanitary } \\
\text { latrine for } \\
\text { defecation } \\
\text { - Discard child } \\
\text { feces into latrine } \\
\text { - Clean feces from } \\
\text { latrine slab, pan } \\
\text { and floor with } \\
\text { water, which } \\
\text { helps reduce flies } \\
\text { and bad smell }\end{array}$ & $\begin{array}{l}\text { Encouraged arsenic } \\
\text { testing of tube well } \\
\text { water } \\
\text { - Use arsenic free safe } \\
\text { water for both } \\
\text { cooking and drinking } \\
\text { Arsenic contaminated } \\
\text { water is harmful for } \\
\text { the baby and pregnant } \\
\text { mother, and other } \\
\text { family members }\end{array}$ \\
\hline
\end{tabular}

FIGURE 1. Summary of audio and video promotion messages, derived from watching/listening to television and radio spots.

2012 (Figure 1). There were a total of 3,381 radio broadcasts and 776 television broadcasts during the campaign.

Study setting and design. We conducted a cross-sectional study from July 2011 through May 2012 to assess the subdistrict level frequency of health behavior outcomes across SHEWA-B intervention subdistricts to measure the quality of intervention implementation. ${ }^{18}$ We leveraged this large crosssectional study to evaluate the SHEWA-B mass media campaign. We classified the data from the first 15 evaluated subdistricts (Figure 2) collected between July and September 2011 just before the mass media campaign as the first round (before mass media campaign). Field-workers conducted a second round of cross-sectional data collection between July and October 2012 after the mass media campaign from the same 15 subdistricts (Figure 3). Because the mass media campaign was broadcast throughout the country, there was no opportunity to enroll a contemporaneous unexposed control group.

Sampling approach. For the first round of data collection, field research assistants implemented a cross-sectional survey with a sample large enough to detect differences in implementation between upazilas. The survey was completed among intervention communities in 60 upazilas, including 30 clusters per upazila and 28 households per cluster, yielding a sample of approximately 277,200 people. Data collection was carried out on a rolling basis, and the number of clusters included in each union was determined using probability proportionate to size sampling. UNICEF subdistricts and union officers kept lists of the villages in each union where SHEWA-B was operating. These lists were reviewed for each union, and the number of villages assigned to each union by probability proportionate sampling was randomly selected from the list. Villages that were previously sampled for SHEWA-B evaluations were excluded from this list. For the second round of data collection, the field team interviewed residents from the same 15 SHEWA-B intervention subdistricts that were evaluated pre-intervention. From each subdistrict sampled, approximately 20 clusters were identified, and then field staff interviewed 28 households per cluster. 


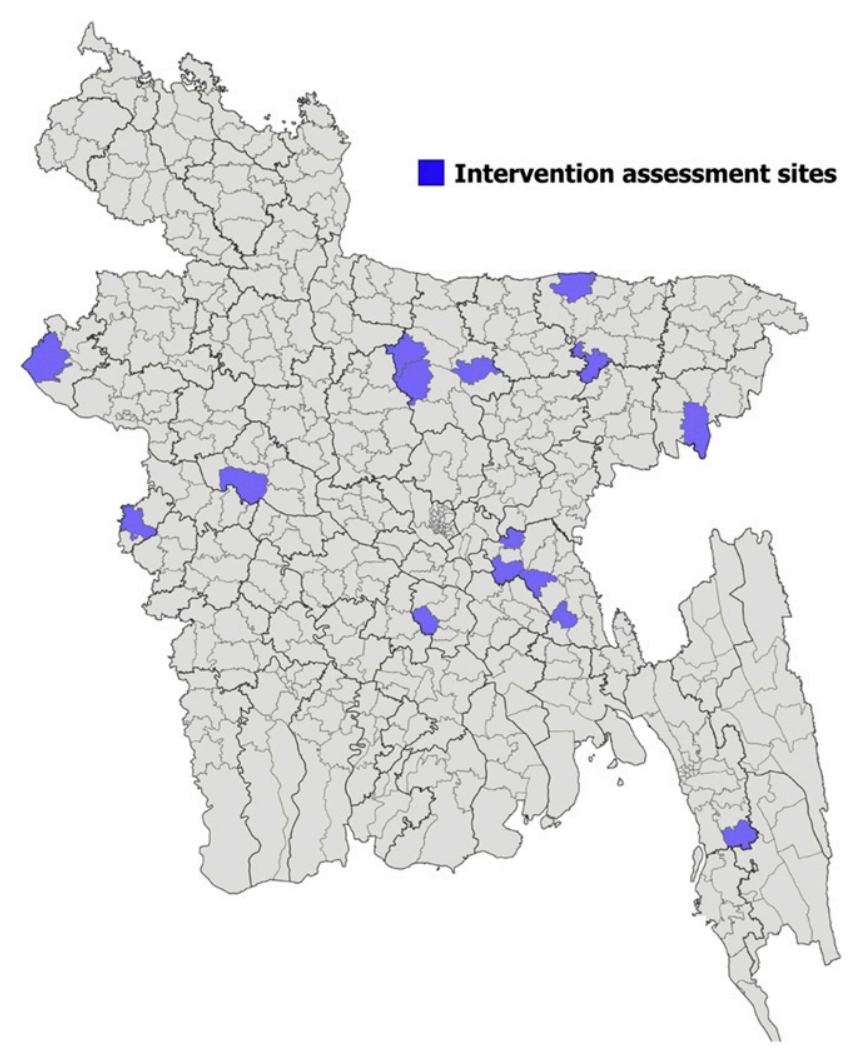

FIGURE 2. Pre- and post-intervention subdistricts of Sanitation, Hygiene Education, and Water Supply in Bangladesh Program mass media campaign study. This figure appears in color at www.ajtmh.org.

In sampled villages, field-workers worked with village residents to identify the central point of the village. Households were considered eligible if at least one child younger than 5 years lived in the household. The study team identified the first eligible household closest to the selected starting point and invited them to participate in the evaluation. Once a household was enrolled, field-workers skipped the next two closest households, and then looked for the next closest eligible household. The process of skipping the two closest households and then seeking to enroll additional households was repeated until the sample from the selected starting point was enrolled. If the next closest household had the same intervention assignment (i.e., intervention or control) but was outside of the union, then the union line was crossed, and the household was enrolled. If the next closest household had a different intervention assignment, then it was ineligible, and the team located the next closest eligible household within the union.
Data collection. Trained field staff from the icddr,b used a pretested structured questionnaire to record reported SHEWA-B messages recalled by the caregiver regarding hygiene practices, water treatment, and latrine use. Field staff assessed handwashing practices by observing handwashing demonstrations and examining the availability of handwashing facilities and cleansing agents such as water and soap in the handwashing station. For the handwashing demonstration, caregivers and children aged 3-5 years were asked to show how they usually wash their hands after defecation. We defined a handwashing station as the location where the respondent reports that she usually washes her hands after defecation and before cooking or eating or feeding child. Field-workers also examined hands of caregiver and children aged $<5$ years (fingernails, finger pads, and palms of each hand) for visible dirt using a three-point scale (visible dirt particles, unclean appearance, and clean). Visible dirt particles were defined as specks of dirt, mud, soil, ash, or any other visible material; unclean appearance was defined as no visible dirt particles but general uncleanliness; and clean was defined as would appear after someone washes hands or takes a bath. In addition, the field staff conducted spot checks to observe household hygiene conditions, drinking water storage containers, sanitation facilities, and latrine cleanliness. We defined stored water in a covered container if all the containers found in a house are fully covered. We classified improved and unimproved latrines using WHO/UNICEF Joint Monitoring Programme definition. ${ }^{25}$ Field-workers classified a latrine that on observation had no visible feces on the latrine slab or floor as clean.

Data analysis. We compared the prevalence of knowledge and practice outcomes among respondents from households visited before the mass media intervention with those visited after the mass media intervention. We compared the following outcomes before and after the mass media campaign: 1) household and caregiver characteristics and WASH facilities; 2) beneficiary health behavior knowledge about water, sanitation, and hygiene; and 3) beneficiary health behavior practices about water, sanitation, and hygiene. We estimated unadjusted and adjusted prevalence ratios (PRs) comparing prevalence after versus before the intervention using generalized linear models with a binomial family and log link function, with robust standard errors to account for the clustering at the village level. In multivariable models, we included all covariates that were associated with the dependent variable at the $P<0.2$ level in bivariate analyses. We used principal component analysis to calculate a household wealth index using assets and housing materials. ${ }^{26,27}$ This index was used as a covariate representing household wealth.

\section{SHEWA-B Program in Bangladesh}

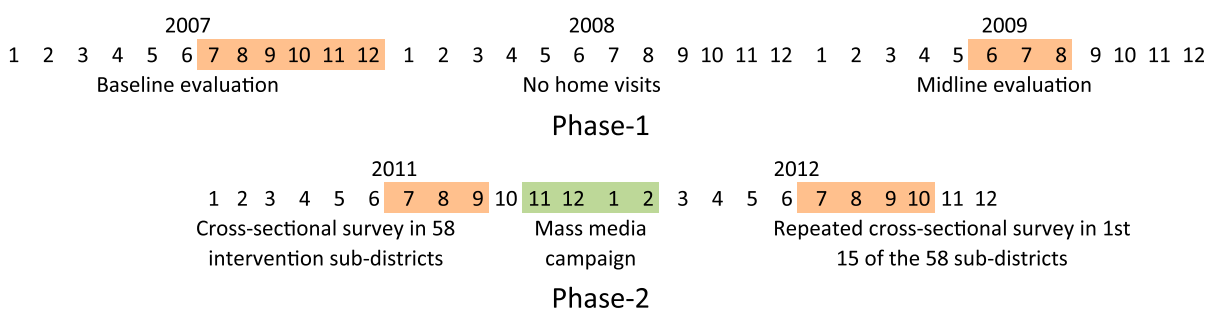

FIgURE 3. Study time line. This figure appears in color at www.ajtmh.org. 
Ethical considerations. All households provided written informed consent. The protocol was reviewed and approved by human subjects review committees at icddr,b (PR-11021) and by an institutional review board at the U.S. CDC.

\section{RESULTS}

Household characteristics. Households enrolled before the mass media campaign were similar to households enrolled after the mass media campaign (Table 1). In both populations, 25\% (before campaign, $n=2,250$, and after campaign, $n=$ $2,081)$ of mothers had no formal education, whereas $37 \%$ ( $n=$ 3,318 ) of fathers interviewed before the campaign had no formal education compared with $39 \%(n=3,317)$ of fathers interviewed after the campaign. Participants enrolled before and after the campaign had similar occupations, were equally likely to own their own homes, and had similar rankings by wealth index (Table 1). About 73\% $(n=6,546)$ and $70 \%(n=$ 5,854 ) of households had shallow tube wells as a source of drinking water before and after the mass media campaign (Table 1). The most frequently observed drinking water storage containers were kalash (a lidless aluminum vessel with a narrow mouth but a wide brim that is typically covered using a plate), $83 \%(n=5,040)$ and $88 \%(n=2,826)$ before and after the campaign, respectively. About $4 \%(n=398)$ of households reported open defecation before the mass media campaign compared with $6 \%(n=532)$ of households after the campaign (Table 1$)$.

Association between mass media campaign and health behaviors. Most of the households recalled at least one massage regarding handwashing both before and after the

TABLE 1

Sociodemographic characteristics of respondents and households before and after mass media campaign in rural Bangladesh

\begin{tabular}{|c|c|c|c|c|}
\hline & \multicolumn{2}{|c|}{ Before mass media campaign $(N=8,947)$} & \multicolumn{2}{|c|}{ After mass media campaign $(N=8,400)$} \\
\hline & $\%(n)$ & $N$ & $N$ & $\%(n)$ \\
\hline Male household head & $95(8,497)$ & 8,400 & 8,947 & $98(8,240)$ \\
\hline Mean age of the respondent (SD) & $27(7)$ & 8,400 & 8,947 & $28(7)$ \\
\hline \multicolumn{5}{|l|}{ Education of mother of the youngest child } \\
\hline No education & $25(2,250)$ & 8,400 & 8,947 & $25(2,081)$ \\
\hline Primary education & $36(3,204)$ & 8,400 & 8,947 & $35(2,902)$ \\
\hline Secondary and above education & $39(3,493)$ & 8,400 & 8,947 & $41(3,417)$ \\
\hline \multicolumn{5}{|l|}{ Education of father of the youngest child } \\
\hline No education & $37(3,318)$ & 8,400 & 8,947 & $39(3,317)$ \\
\hline Primary education & $31(2,754)$ & 8,400 & 8,947 & $29(2,440)$ \\
\hline Secondary and above education & $32(2,875)$ & 8,400 & 8,947 & $31(2,643)$ \\
\hline \multicolumn{5}{|l|}{ Occupation of father of the youngest child } \\
\hline Agri and non-agri labor & $20(1,779)$ & 8,400 & 8,947 & $19(1,600)$ \\
\hline $\begin{array}{l}\text { Farmer/cultivator/landlord/poultry/ } \\
\text { livestock/rearer/homemaker }\end{array}$ & $20(1,802)$ & 8,400 & 8,947 & $22(1,875)$ \\
\hline Service & $9(764)$ & 8,400 & 8,947 & $9(737)$ \\
\hline Skilled worker/profession & $7(631)$ & 8,400 & 8,947 & 7 (595) \\
\hline Rickshaw/van puller & $10(933)$ & 8,400 & 8,947 & $11(891)$ \\
\hline Traders/business occupation & $18(1,638)$ & 8,400 & 8,947 & $18(1,520)$ \\
\hline Staying abroad & $9(785)$ & 8,400 & 8,947 & $9(724)$ \\
\hline \multicolumn{5}{|l|}{ Ownership of house } \\
\hline Self-owned & $95(8,496)$ & 8,400 & 8,947 & $94(7,906)$ \\
\hline Rental & $1(90)$ & 8,400 & 8,947 & $1(109)$ \\
\hline Government land & $1(81)$ & 8,400 & 8,947 & $1(90)$ \\
\hline Owned by a landlord & $1(132)$ & 8,400 & 8,947 & $1(117)$ \\
\hline Mean number of household rooms (SD) & $2.12(1.27)$ & 8,400 & 8,930 & $2.10(1.27)$ \\
\hline \multicolumn{5}{|l|}{ Wealth index ${ }^{*}$} \\
\hline Low & $34(3,005)$ & 8,400 & 8,947 & $33(2,778)$ \\
\hline Medium & $33(2,927)$ & 8,400 & 8,947 & $34(2,860)$ \\
\hline High & $33(3,015)$ & 8,400 & 8,947 & $33(2,762)$ \\
\hline \multicolumn{5}{|l|}{ Main fuel used for cooking } \\
\hline Crop residue/grass/dung cakes & $64(5,737)$ & 8,400 & 8,928 & $70(5,864)$ \\
\hline Wood & $34(3,106)$ & 8,400 & 8,928 & $28(2,371)$ \\
\hline Liquid gas/biogas & $0.50(45)$ & 8,400 & 8,928 & $1.4(119)$ \\
\hline Coal/coke/lignite/charcoal & $0.45(40)$ & 8,400 & 8,928 & $0.54(45)$ \\
\hline \multicolumn{5}{|l|}{ Source of drinking water } \\
\hline Shallow tube well & $73(6,546)$ & 8,400 & 8,939 & $70(5,854)$ \\
\hline Deep tube well & $22(1,964)$ & 8,400 & 8,939 & $24(1,998)$ \\
\hline $\begin{array}{l}\text { Household alone own drinking water } \\
\text { point }\end{array}$ & $30(2,650)$ & 8,400 & 8,938 & $32(2,680)$ \\
\hline \multicolumn{5}{|l|}{ Primary drinking water storage container† } \\
\hline Kalash (narrow-mouthed container) $\ddagger$ & $83(5,040)$ & 3,221 & 6,049 & $88(2,826)$ \\
\hline Pitcher (wide-mouthed container) & $47(2,825)$ & 3,221 & 6,049 & $32(1,037)$ \\
\hline \multicolumn{5}{|c|}{ Type of toilet facility the household members usually used } \\
\hline Open defecation & $4(398)$ & 8,400 & 8,933 & $6(532)$ \\
\hline Unimproved latrine§ & $59(5,292)$ & 8,400 & 8,933 & $53(4,454)$ \\
\hline Improved latrine§ & $36(3,243)$ & 8,400 & 8,933 & $41(3,413)$ \\
\hline
\end{tabular}

*Wealth index calculated as tertiles from principal component analysis of household assets.
† Multiple drinking water storage containers were reported by some households this is why these proportions sum to greater than $100 \%$.

$\ddagger$ Kalash is a lidless aluminum vessel with a narrow mouth but a wide brim that is typically covered using a plate.

$\ddagger$ Kalash is a lidless aluminum vessel with a narrow mouth but a wide brim that is typically covered using a plate.
$\S$ Defined using WHO/UNICEF Joint Monitoring Programme definition for improved and unimproved latrine. ${ }^{25}$ 
campaign (Table 2). Before the mass media campaign, $40 \%$ $(n=3,542)$ of participants recalled at least three messages on handwashing, $15 \%(n=1,306)$ on safe water, and $32 \%(2,891)$ on sanitation, whereas after the campaign, $57 \%(n=4,797)$ of participants recalled at least three messages on handwashing, $19 \%(n=1,592)$ on safe water, and $50 \%(n=4,198)$ on sanitation (Table 2). In bivariate analysis, the prevalence of households recalling at least one message was significantly higher after the campaign for handwashing ( $P R=1.64$, 1.45-1.84), safe water (1.29, 1.17-1.42), and latrine use and feces disposal $(P R=1.68,1.49-1.89)$. The prevalence of households recalling at least three messages was significantly higher as well, suggesting improvement of caregiver's knowledge regarding target behaviors messages (Table 2).

Observed health behaviors also improved after the mass media campaign in bivariate analyses. During handwashing demonstration, we found that before the mass media campaign, $67 \%$ ( $n=5,807)$ of caregiver and 53\% $(n=845)$ of children aged 3-5 years used soap and water, whereas after mass media campaign, $79 \%(n=6,207)$ of caregiver and $69 \%$ ( $n=613$ ) of children aged 3-5 years used soap and water (Table 3). In bivariate analysis, we found that using soap and water by caregiver was $1.17(\mathrm{Cl}: 1.13,1.21)$ times higher and by children aged $3-5$ years was $1.30(\mathrm{Cl}: 1.19,1.40)$ times higher among household after mass media campaign than before mass media campaign (Table 3). Before mass media campaign, the prevalence of no visible dirt on hands of caregivers and children aged $3-5$ years was $41 \%(n=3,616)$ and $27 \%$ ( $n=2,264)$, whereas after mass media campaign, the prevalence was $47 \%(n=3,889)$ for caregiver and $30 \%(2,380)$ for children aged $3-5$ years (Table 3 ). In bivariate analysis, the prevalence of no visible dirt on hands of caregivers $(P R=1.14$, $1.07-1.20)$ and children aged $3-5$ years $(P R=1.13,1.05-1.21)$ was more common after mass media campaign than before mass media campaign (Table 3).

There were also significant improvements in the prevalence of a convenient handwashing station available with water and soap usually used after defecation $(P R=1.19,1.06-1.33)$ and before cooking or eating or feeding child $(P R=1.12$, 1.03-1.22) (Table 4). After the mass media campaign, a higher percentage of households had covered stored drinking water container ( $P R=1.34,1.21-1.48)$ and access to improved latrine ( $P R=1.10,1.03-1.19)$ (Table 4). The PRs estimated in the bivariate and multivariable analysis were similar.

\section{DISCUSSION}

Following the mass media campaign, about half of the households recalled at least three messages regarding handwashing, latrine use, and feces disposal, and one-fifth of the households recalled safe water messages; most of the households recalled at least one message. The recall of messages was significantly improved compared with before the campaign, suggesting that mass media can successfully change knowledge of targeted behavioral messages. We also found improvements in observed behavior indicators, including visibly cleaner child and caregiver hands, availability of water and soap for handwashing, covered drinking water storage containers, and presence of improved latrines. Although increased knowledge does not necessarily translate into target practices, ${ }^{28}$ these results demonstrate improvements in both knowledge and practices following the mass media campaign.

Although measuring handwashing behavior is difficult, the simplest and cheapest method for measuring handwashing with soap is to ask respondents to self-report their behavior. However, respondents tend to overreport handwashing because of courtesy bias, ${ }^{29}$ especially if they know that handwashing with soap is recommended. In our study, we measured the handwashing practice by observing handwashing demonstration, visible hand cleanliness, and availability of handwashing facilities and cleansing agents. We chose not to use structured observation, because of expense and our prior work in rural Bangladesh demonstrating that the presence of an observer substantially alters handwashing behavior. ${ }^{30}$

Behavior change is complex, and the evidence for a beneficial effect of traditional hygiene education in low- and middleincome countries is limited. ${ }^{31,32}$ Our findings of improved recall and behaviors following the mass media campaign contrast with our previous findings from the large-scale inperson SHEWA-B campaign to promote water, sanitation, and hygiene-related behaviors in these areas during the first 18 months of the intervention. Approximately half of the respondents did not recall ever meeting a SHEWA-B hygiene promoter. ${ }^{18}$ Moreover, recall of key messages by hygiene promoters was low, ${ }^{18}$ suggesting a poorly implemented program. Indeed, 18 months of SHEWA-B intervention did not substantially improve targeted behaviors. ${ }^{24}$ Moreover, health behaviors and access to hygiene and sanitation infrastructure

TABLE 2

Sanitation, Hygiene Education, and Water Supply in Bangladesh Program handwashing, sanitary latrine use, and feces disposal and safe water message recall by beneficiaries before and after the mass media campaign in rural Bangladesh

\begin{tabular}{|c|c|c|c|c|}
\hline & $\begin{array}{l}\text { Before mass media campaign } \\
\qquad(N=8,947)\end{array}$ & $\begin{array}{l}\text { After mass media campaign } \\
\qquad(N=8,400)\end{array}$ & Bivariate model ${ }^{*}$ & Multivariable model $\dagger$ \\
\hline Recalled messages & $\%(n)$ & $\%(n)$ & $\mathrm{PR}(95 \% \mathrm{Cl})$ & $\mathrm{PR}(95 \% \mathrm{Cl})$ \\
\hline \multicolumn{5}{|c|}{ Able to state at least one message included in the SHEWA-B mass media campaign on } \\
\hline Handwashing & $71(6,324)$ & $85(7,141)$ & $1.64(1.45,1.84)$ & $1.65(1.46,1.85)$ \\
\hline Handwashing & $71(6,324)$ & $85(7,141)$ & $1.64(1.45,1.84)$ & $1.65(1.46,1.85)$ \\
\hline Safe water & $62(5,506)$ & $72(6,055)$ & $1.29(1.17,1.42)$ & $1.30(1.18,1.43)$ \\
\hline Sanitary latrine use and feces disposal & $68(6,125)$ & $84(7,075)$ & $1.68(1.49,1.89)$ & $1.69(1.50,1.90)$ \\
\hline \multicolumn{5}{|c|}{ Able to state at least three messages included in the SHEWA-B mass media campaign on } \\
\hline Handwashing & $40(3,542)$ & $57(4,797)$ & $1.44(1.34,1.55)$ & $1.45(1.35,1.56)$ \\
\hline Safe water & $15(1,306)$ & $19(1,592)$ & $1.17(1.08,1.26)$ & $1.17(1.08,1.26)$ \\
\hline Sanitary latrine use and feces disposal & $32(2,891)$ & $50(4,198)$ & $1.45(1.35,1.55)$ & $1.46(1.36,1.56)$ \\
\hline
\end{tabular}

PR = prevalence ratio; SHEWA-B = Sanitation, Hygiene Education, and Water Supply in Bangladesh Program. Values in bold indicate prevalence ratios that are statistically significant at the $P<0.05$ level. * We estimated the prevalence ratio by using generalized linear model to adjust for clustering

† Multivariable model includes all covariates associated with the outcome variables in bivariate analyses at the $P<0.2$ level. 
TABLE 3

Demonstrated handwashing behavior and hand cleanliness of the beneficiaries (caregivers and children aged $3-5$ years) before and after the mass media campaign in rural Bangladesh

\begin{tabular}{|c|c|c|c|c|c|c|}
\hline & \multicolumn{2}{|c|}{$\begin{array}{l}\text { Before mass media } \\
\text { campaign }\end{array}$} & \multicolumn{2}{|c|}{ After mass media campaign } & \multirow{2}{*}{$\frac{\text { Bivariate model }^{\star}}{\text { PR }(95 \% \mathrm{Cl})}$} & \multirow{2}{*}{$\frac{\text { Multivariable model† }}{\text { PR }(95 \% \mathrm{Cl})}$} \\
\hline & $N$ & $\%(n)$ & $N$ & $\%(n)$ & & \\
\hline \multicolumn{7}{|c|}{ Caregiver demonstrated handwashing behavior after defecation } \\
\hline Used only water & 8,611 & $18(1,517)$ & 7,871 & $11(894)$ & $0.62(0.52,0.73)$ & $0.65(0.57,0.74)$ \\
\hline Used soap and water & 8,611 & $67(5,807)$ & 7,871 & $79(6,207)$ & $1.17(1.13,1.21)$ & $1.15(1.12,1.19)$ \\
\hline Washed both hands & 8,611 & $72(6,201)$ & 7,871 & $80(6,332)$ & $1.12(1.10,1.15)$ & $1.11(1.08,1.15)$ \\
\hline Caregiver dried hands & 8,611 & $85(7,280)$ & 7,871 & $92(7,268)$ & $1.09(1.07,1.11)$ & $1.09(1.07,1.11)$ \\
\hline Hands dried with clean clothes or air & 7,280 & $5(340)$ & 7,268 & $1.7(125)$ & $0.37(0.27,0.49)$ & $0.36(0.27,0.48)$ \\
\hline \multicolumn{7}{|c|}{ Children aged $3-5$ years demonstrated handwashing behavior after defecation } \\
\hline Used only water & 1,580 & $35(559)$ & 885 & $24(209)$ & $0.67(0.56,0.79)$ & $0.66(0.56,0.78)$ \\
\hline Used soap and water & 1,580 & $53(845)$ & 885 & $69(613)$ & $1.30(1.19,1.40)$ & $1.31(1.22,1.41)$ \\
\hline Washed both hands & 1,580 & $79(1,240)$ & 885 & $85(756)$ & $1.09(1.03,1.14)$ & $1.09(1.04,1.15)$ \\
\hline Children dried hands & 1,580 & $58(926)$ & 885 & 77 (682) & $1.32(1.23,1.41)$ & $1.31(1.22,1.41)$ \\
\hline Hands dried with clean clothed or air & 926 & 13 (122) & 682 & $8.2(56)$ & $0.62(0.42,0.93)$ & $0.63(0.42,0.95)$ \\
\hline $\begin{array}{l}\text { No visible dirt on caregiver nails, palms, } \\
\text { and finger pads }\end{array}$ & 8,882 & $41(3,616)$ & 8,361 & $47(3,889)$ & $1.15(1.09,1.21)$ & $1.14(1.07,1.20)$ \\
\hline $\begin{array}{l}\text { No visible dirt on child nails, palms, and } \\
\text { finger pads }\end{array}$ & 8,486 & $27(2,264)$ & 7,883 & $30(2,380)$ & $1.13(1.04,1.22)$ & $1.13(1.05,1.21)$ \\
\hline
\end{tabular}

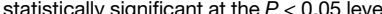

* We estimated the PR by using generalized linear model to adjust for clustering.

$\dagger$ Multivariable model includes all covariates associated with the outcome variables in bivariate analyses at the $P<0.2$ level.

were similar whether or not participants had met a SHEWA-B promoter, ${ }^{18}$ further demonstrating the ineffectiveness of the interpersonal communication intervention deployed within SHEWA-B study area. By contrast, the data presented in this article suggest that the subsequent SHEWA-B mass media campaign was more effective in improving both knowledge and practice than the earlier interpersonal communication approach.

The evidence of the effect of mass media in improving water, sanitation, and hygiene-related health behavior knowledge and practices is mixed. A study in Tanzania found a positive association of media access with increased water, sanitation, and hygiene knowledge, ${ }^{33}$ and another study in Ghana found that a handwashing campaign strongly increased awareness of the importance of washing hands with soap, ${ }^{34}$ consistent with the findings of our study. Our findings were also similar to those of a study in Kenya that showed a positive association between media access and an increase in handwashing with soap (24\%). ${ }^{35}$ A cross-sectional study conducted in Bangladesh similarly identified a strong association between television access and handwashing practices. ${ }^{25}$

By contrast, a study conducted in Peru found that an intervention based solely on radio messages had no significant effect on exposure to the handwashing promotion campaign messages and no effect on the availability of soap for handwashing, and concluded there was no effect on handwashing knowledge or handwashing behavior. ${ }^{36}$

The Bangladesh radio and television campaign was aired in the entire country; therefore, it was not possible to enroll a contemporaneous control group to compare the difference in health behavior knowledge and health behavior. It is possible that our findings reflect secular trends in knowledge and

TABLE 4

Household water, sanitation, and hygiene practices before and after the mass media campaign in rural Bangladesh

\begin{tabular}{|c|c|c|c|c|c|c|}
\hline & \multicolumn{2}{|c|}{$\begin{array}{l}\text { Before mass media } \\
\text { campaign }\end{array}$} & \multicolumn{2}{|c|}{ After mass media campaign } & \multirow{2}{*}{$\begin{array}{c}\text { Bivariate model }{ }^{\star} \\
\text { PR }(95 \% \mathrm{Cl})\end{array}$} & \multirow{2}{*}{$\frac{\text { Multivariable model† }}{\mathrm{PR}(95 \% \mathrm{Cl})}$} \\
\hline & N & $\%(n)$ & N & $\%(n)$ & & \\
\hline \multicolumn{7}{|c|}{ Convenient hand washing location available with water and soap $\ddagger$} \\
\hline Usually washed hands after defecation & 7,123 & $18(1,291)$ & 7,272 & $22(1,566)$ & $1.19(1.06,1.33)$ & $1.12(1.06,1.19)$ \\
\hline $\begin{array}{l}\text { Usually washed hands before cooking } \\
\text { or eating or feeding child }\end{array}$ & 5,243 & $34(1,797)$ & 7,095 & $38(1,988)$ & $1.12(1.03,1.22)$ & $1.09(1.01,1.18)$ \\
\hline \multicolumn{7}{|l|}{ Stored drinking water in a covered container§ } \\
\hline Kalash (narrow-mouthed container) & 5,040 & $47(2,369)$ & 2,826 & $63(1,779)$ & $1.34(1.21,1.48)$ & $1.37(1.24,1.51)$ \\
\hline Pitcher (wide-mouthed container) & 2,825 & $29(825)$ & 1,037 & $32(330)$ & $1.09(0.93,1.29)$ & $1.15(0.98,1.35)$ \\
\hline \multicolumn{7}{|l|}{ Households sanitation } \\
\hline No access to latrine & 8,933 & $4(392)$ & 8,399 & $4(354)$ & $1.00(0.83,1.16)$ & $0.98(0.84,1.15)$ \\
\hline Have access to an improved latrine & 8,541 & $33(2,780)$ & 8,045 & $37(2,974)$ & $1.10(1.03,1.19)$ & $1.12(1.04,1.20)$ \\
\hline Cleanliness of latrine\# & 7,990 & $46(3,713)$ & 7,248 & $46(3,356)$ & $1.00(0.94,1.05)$ & $1.01(0.95,1.06)$ \\
\hline
\end{tabular}

* We estimated the PR by using generalized linear model to adjust for clustering.

† Multivariable model includes all covariates associated with the outcome variables in bivariate analyses at the $P<0.2$ level.

$\ddagger$ Convenient is defined as the location where the respondent reports that she usually washes her hands after defecation and before cooking or eating or feeding child.

$\S$ If all the containers found in a house is fully covered, then the households is considered to store water in a covered container. The denominator is the number of households that store water in a container.

"No access to latrine is defined as no latrine facility/defecated in bush/open field.

- Defined using WHO/UNICEF Joint Monitoring Programme definition for improved latrine.

\# Cleanliness of latrines is defined as feces were not observed on the latrine slab or floor. 
behaviors that coincided with the timing of the mass media campaign. However, we are unaware of any interventions in these communities that would have generated such an effect. It is also possible that population characteristics associated with improved behaviors increased over time or that the before and after cross-sectional samples captured participants with different characteristics. However, we found similar PRs estimated in the bivariate and multivariable analysis, suggesting no evidence of substantial confounding by measured household characteristics between the two cross-sectional sets of households enrolled for data collection before and after the mass media campaign. The data collectors were not blinded; therefore, enumerators could have been subject to bias in their data collection related to this unblinded intervention.

In our study setting, over the 1-year period when the mass media campaign was aired, we found increased hygiene message recall by caregivers and increased observed health behaviors. Considering the low cost per household reached by mass media compared to in-person communication, this approach can be deployed to improve water, sanitation, and hygiene practices and should be evaluated in other contexts.

Received September 7, 2020. Accepted for publication November 16, 2020.

Published online January 18, 2021.

Note: Supplemental materials appear at www.ajtmh.org.

Acknowledgments: This study was funded by UNICEF, grant number GR-00828. International Centre For Diarrhoeal Disease and Research, Bangladesh (icddr,b) acknowledges with gratitude the commitment of UNICEF and Department for International Development to its research efforts. The International Centre for Diarrhoeal Disease Research, Bangladesh is also grateful to the governments of Bangladesh, Canada, Sweden, and the United Kingdom for providing core/unrestricted support. We would like to thank the participants for donating their time and the field team for collecting the data. We also thank all the collaborators engaged in the study.

Financial support: This research was financially supported by UNICEF.

Authors' addresses: Mahfuza Islam, Sonia Sultana, Leanne Unicomb, and Mahbubur Rahman, Environmental Intervention Unit, Infectious Disease Division, icddr,b, Dhaka, Bangladesh, E-mails: mi_sheuli@ icddrb.org, sonia.sultana@icddrb.org, leanne.unicomb60@gmail.com, and mahbubr@icddrb.org. Jade Benjamin-Chung, Division of Epidemiology and Biostatistics, University of California, Berkeley, Berkeley, CA, E-mail: jadebc@berkeley.edu. Monirul Alam, WASH Specialist, Water, Sanitation and Hygiene (WASH) Section, UNICEF, Dhaka, Bangladesh, E-mail: malam@unicef.org. Ayse Ercumen, Department of Forestry and Environmental Resources, North Carolina State University, Raleigh, NC, E-mail: aercumen@gmail.com. Stephen P. Luby, Woods Institute for the Environment, Stanford University, Stanford, CA, E-mail: sluby@stanford.edu.

This is an open-access article distributed under the terms of the Creative Commons Attribution (CC-BY) License, which permits unrestricted use, distribution, and reproduction in any medium, provided the original author and source are credited.

\section{REFERENCES}

1. Hendley JO, Wenzel RP, Gwaltney JM Jr., 1973. Transmission of rhinovirus colds by self-inoculation. New Engl J Med 288: 1361-1364.

2. Haefliger $P$, Mathieu-Nolf M, Lociciro S, Ndiaye C, Coly M, Diouf A, Faye AL, Sow A, Tempowski J, Pronczuk J, 2009. Mass lead intoxication from informal used lead-acid battery recycling in Dakar, Senegal. Environ Health Perspect 117: 1535-1540.
3. Kwong LH, Ercumen A, Pickering AJ, Unicomb L, Davis J, Luby SP, 2020. Age-related changes to environmental exposure: variation in the frequency that young children place hands and objects in their mouths. J Exp Sci Environ Epidemiol 30: 205-216.

4. Ejemot-Nwadiaro RI, Ehiri JE, Meremikwu MM, Critchley JA, 2008. Hand washing for preventing diarrhoea. Cochrane Database Syste Rev 23: CD004265.

5. Curtis V, Cairncross S, 2003. Effect of washing hands with soap on diarrhoea risk in the community: a systematic review. Lancet Infecti Dis 3: 275-281.

6. Luby SP, Agboatwalla M, Feikin DR, Painter J, Billhimer W, Altaf A, Hoekstra RM, 2005. Effect of handwashing on child health: a randomised controlled trial. Lancet 366: 225-233.

7. Rabie T, Curtis V, 2006. Handwashing and risk of respiratory infections: a quantitative systematic review. Trop Med Int Health 11: 258-267.

8. Ma QX, Shan H, Zhang HL, Li GM, Yang RM, Chen JM, 2020. Potential utilities of mask-wearing and instant hand hygiene for fighting SARS-CoV-2. J Med Virol 92: 1567-1571.

9. Jefferson T, Del Mar C, Dooley L, Ferroni E, Al-Ansary LA, Bawazeer GA, Van Driel ML, Foxlee R, Rivetti A, 2009. Physical interventions to interrupt or reduce the spread of respiratory viruses: systematic review. Br Med J 339: b3675.

10. CDC, 2020. Show Me the Science - How to Wash Your Hands Handwashing. Available at: https://www.cdc.gov/handwashing/ show-me-the-science-handwashing.html. Accessed August 5, 2020.

11. Freeman MC, Greene LE, Dreibelbis R, Saboori S, Muga R, Brumback $B$, Rheingans $R, 2012$. Assessing the impact of a school-based water treatment, hygiene and sanitation programme on pupil absence in Nyanza province, Kenya: a clusterrandomized trial. Trop Med Int Health 17: 380-391.

12. Scott B, Curtis V, Rabie T, 2003. Protecting children from diarrhoea and acute respiratory infections: the role of handwashing promotion in water and sanitation programmes. WHO Reg Health Forum 7: 42-47.

13. Curtis VA, Danquah LO, Aunger RV, 2009. Planned, motivated and habitual hygiene behaviour: an eleven country review. Health Educ Res 24: 655-673.

14. Clasen TF, Alexander KT, Sinclair D, Boisson S, Peletz R, Chang $\mathrm{HH}$, Majorin F, Cairncross S, 2015. Interventions to improve water quality for preventing diarrhoea. Cochrane Database Syst Rev 2015: CD004794.

15. Ejemot-Nwadiaro RI, Ehiri JE, Arikpo D, Meremikwu MM, Critchley JA, 2015. Hand washing promotion for preventing diarrhoea. Cochrane Database Syst Rev 2015: CD004265.

16. Wolf J, Prüss-Ustün A, Cumming $O$, Bartram J, Bonjour S, Cairncross S, Clasen T, Colford JM Jr., Curtis V, De France J, 2014. Systematic review: assessing the impact of drinking water and sanitation on diarrhoeal disease in low-and middleincome settings: systematic review and meta-regression. Trop Med Int Health 19: 928-942.

17. Pickering AJ, Null C, Winch PJ, Mangwadu G, Arnold BF, Prendergast AJ, Njenga SM, Rahman M, Ntozini R, BenjaminChung J, 2019. The WASH benefits and SHINE trials: interpretation of WASH intervention effects on linear growth and diarrhoea. Lancet Glob Health 7: e1139-e1146.

18. Benjamin-Chung J, Sultana S, Halder AK, Ahsan MA, Arnold BF, Hubbard AE, Unicomb L, Luby SP, Colford JM Jr., 2017. Scaling up a water, sanitation, and hygiene program in rural Bangladesh: the role of program implementation. Am J Public Health 107: 694-701.

19. Wakefield MA, Loken B, Hornik RC, 2010. CSU 169/2011: use of mass media campaigns to change health behavior. Lancet 376 : $1261-1271$.

20. Babor T, Caetano R, Casswell S, Edwards G, Giesbrecht N, Graham K, Holder H, 2003. No Ordinary Commodity: Alcohol and Public Policy. Oxford, United Kingdom: Oxford University Press.

21. Madajewicz M, Pfaff A, Van Geen A, Graziano J, Hussein I, Momotaj $\mathrm{H}$, Sylvi R, Ahsan H, 2007. Can information alone change behavior? Response to arsenic contamination of groundwater in Bangladesh. J Dev Econ 84: 731-754.

22. Banerjee AV, Duflo E, Glennerster R, Kothari D, 2010. Improving immunisation coverage in rural India: clustered randomised 
controlled evaluation of immunisation campaigns with and without incentives. Br Med J 340: c2220.

23. Summerbell CD, Waters E, Edmunds L, Kelly SA, Brown T, Campbell KJ, 2005. Interventions for preventing obesity in children. Cochrane Database Syst Rev 3: CD001871.

24. Huda TMN, Unicomb L, Johnston RB, Halder AK, Sharker MAY, Luby SP, 2012. Interim evaluation of a large scale sanitation, hygiene and water improvement programme on childhood diarrhea and respiratory disease in rural Bangladesh. Soc Sci Med 75: 604-611.

25. Rabbi SE, Dey NC, 2013. Exploring the gap between hand washing knowledge and practices in Bangladesh: a crosssectional comparative study. BMC Public Health 13: 89.

26. Vyas SKL, 2006. Constructing socio-economic status indices: how to use principal components analysis. Health Policy Plan 21: 459-468.

27. Howe LD, Galobardes B, Matijasevich A, Gordon D, Johnston D, Onwujekwe O, Patel R, Webb EA, Lawlor DA, Hargreaves JR, 2012. Measuring socio-economic position for epidemiological studies in low-and middle-income countries: a methods of measurement in epidemiology paper. Int $J$ Epidemiol 41: 871-886.

28. Curtis V, Cousens S, Mertens T, Traore E, Kanki B, Diallo I, 1993. Structured observations of hygiene behaviours in Burkina Faso: validity, variability, and utility. Bull World Health Organ 71: 23-32.

29. Standish T 2017. A Validation Study of Self-reported Behavior: Can College Student Self-reports of Behavior be Accepted as Being Self-evident? (Doctoral dissertation). Retrieved from NC State University Electronic Theses and Dissertations. (Accession no. 33607).
30. Ram PK, Halder AK, Granger SP, Jones T, Hall P, Hitchcock D, Wright R, Nygren B, Islam MS, Molyneaux JW, 2010. Is structured observation a valid technique to measure handwashing behavior? Use of acceleration sensors embedded in soap to assess reactivity to structured observation. Am J Trop Med Hyg 83: 1070-1076.

31. Loevinsohn BP, 1990. Health education interventions in developing countries: a methodological review of published articles. Int J Epidemiol 19: 788-794.

32. Biran A, Hagard S, 2003. Hygiene Promotion: Evidence and Practice. London, United Kingdom: London School of Hygiene and Tropical Medicine.

33. Alexander CC, Shrestha S, Tounkara MD, Cooper S, Hunt L, Hoj TH, Dearden K, Kezakubi D, Atugonza V, West J, 2019. Media access is associated with knowledge of optimal water, sanitation and hygiene practices in Tanzania. Int $J$ Env Res Public Health 16: 1963.

34. Scott BE, Schmidt WP, Aunger R, Garbrah-Aidoo N, Animashaun $R, 2008$. Marketing hygiene behaviours: the impact of different communication channels on reported handwashing behaviour of women in Ghana. Health Educ Res 23: 392-401.

35. Schmidt WP, Aunger R, Coombes Y, Maina PM, Matiko CN, Biran $A$, Curtis V, 2009. Determinants of handwashing practices in Kenya: the role of media exposure, poverty and infrastructure. Trop Med Int Health 14: 1534-1541.

36. Galiani S, Gertler P, Orsola-Vidal A, 2012. Promoting Handwashing Behavior in Peru: The Effect of Large-scale Massmedia and Community Level Interventions. World Bank Policy Research Working Paper 6257. Washington, DC: The World Bank. 